Public Health and Social Services. 6th ed. By L. Farrer-Brown and $M$. Warren. (Pp. 166; 15s.) London: Arnold. 1965.

The appearance of the sixth edition of this useful little handbook is a testimony to its wide popularity. The balance of the subject matter reflects its primary purpose -a textbook for student midwives-but it is comprehensive in scope and can be recommended as a useful introduction for medical students, student health visitors, and industrial nurses, and indeed anyone who seeks a brief but reliable account of British health and welfare services.

Extensive revision has brought the subject matter up to date, but, as the authors remark, social legislation and provision is a continually evolving process. For future editions they might consider whether sufficient emphasis is given to such important matters as hospital social services and the developing field of social work in the community. Similarly, within the public health field refuse disposal receives three times the amount of space accorded to clean air-hardly a fair balance in relation to modern problems.

These are, however, relatively minor drawbacks, and the authors are to be congratulated on their concise and lucid work.

R. A. N. HITCHENS

Radiological Monitoring of the Environment. Edited by B. C. Godbold and J. K. Jones. (Pp. xvi +425 illustrated. I IOs.) Oxford: Pergamon Press. 1965.

This volume records the proceedings of a symposium at Berkeley, Gloucestershire, in October 1963, organized by the Central Electricity Generating Board in association with the Joint Health Physics Committee. It is concerned mainly with environmental monitoring for both natural and artificial radioactivity, and the 27 papers presented at the symposium are reproduced in full in part I of the book. These papers had been circulated in advance to all participants, and part II comprises the authors' introductions of the three general papers which formed the foundation of the meeting, the presentations of three rapporteurs who dealt with the other 24 papers, and the ensuing discussions.

The titles of the three general papers are: Radioactivity in Agricultural Products and its Assessment by Environmental Survey; The Monitoring of Artificial Radioactivity in Waters round the British Isles; and Derived 'Maximum Permissible Levels' used in Neighbourhood and Working Environment Surveys. The subjects of the three rapporteur sessions are: Recent Advances in Monitoring for Air-borne Radioactivity; Current Practice in the Survey of Working Environments; and Current Practice in Neighbourhood Environmental Survey and Possible Alternatives Thereto.

Although the emphasis throughout is on the problems resulting from the operation of nuclear reactors and atomic energy establishments, considerable stress is also laid, especially in the second rapporteur session, on monitoring requirements for industry, hospitals, and research laboratories.

S. K. STEPHENSON
Current Medical Research. A reprint of the articles in the Report of the Medical Research Council October 1963-March 1965 (Cmnd. 2787). (Pp. iv + 64; 4 figures, IV plates. 6s. 6d.) London: H.M.S.O. 1966.

This handy document describes in a little over 60 pages the advancing edge of medicine in the United Kingdom. It does not confine itself solely to work sponsored by the Medical Research Council, but it gives a balanced view of each field with which it deals. Computers, cancer, and colds take up about a third of the booklet; biological standards, child development in the tropics, and diurnal physiological rhythms, another third. The publication is completed by reference to advances in our knowledge of human efficiency under unpleasant conditions, and of accidents and the work of some of the Medical Research Council research establishments. Those selected for mention show where the emphasis lies in modern medical research. Psychiatry, epidemiology, and genetics are the three main fields, together with air pollution, cell metabolism, gastroenterology and blood groups. The work of the National Institute for Medical Research is briefly mentioned with its 40 different research projects, illustrated by examples of virus structure and mechanism, tissue storage and transplantation, protein synthesis, and body temperature control.

For someone who wishes to know what is going on in the main fields of British medical research this publication makes the most interesting reading.

\section{R. C. BROWNE}

Lehrbuch der Arbeitsmedizin, Band II, Spezielle Berufsgefährungen und Schutzmassnahmen. (Textbook of Occupational Medicine. Volume II. Special Dangers of Occupations and Protective Measures.) By Franz Koelsch and Eugen Lederer. (Pp. xii + 65I; No price stated.) Stuttgart: Ferdinand Enke. 1966.

Eye trouble has forced Dr. Koelsch to obtain the assistance of Dr. Lederer in revising, for its 3 rd edition, the second volume of his textbook. This volume presents the risk to health from accidents and disease, not only in occupations where notifiable diseases are met with, but in every occupation. Occupations are collected into groups ranging from Agriculture, Group I, to Home Work, Group 28. Many occupations not usually thought of in connexion with industrial medicine find at least a mention: commercial travellers, for example, in the group of business and office work. On the other hand, many hazards prominent in present-day literature are placed in proportion to other hazards in the occupation. The reference to cadmium in the manufacture of alloys is simply 'the fumes of the recently much employed cadmium are intensely irritating'.

Each of the $\mathbf{2 8}$ groups comprises a number of industries often of different types. By far the greatest space is devoted to the chemical industry because of its scope and the variety and danger of the hazards incurred. In starting to discuss this group there is a remark that has a familiar ring, 'The most dangerous work could be carried out without much danger, if only the necessary technical and hygienic precautions were properly 
observed'. The processes in each individual industry or occupation are described, and then follows an account of the hazards that may arise. This account is usually comprehensive and may, as in Motor Car Driving, include conditions that increase the risk. A leaflet issued by the State Medical Council concerning drugs which may affect driving, i.e., narcotics, tranquillizers, antihistamines, and hypotensives, advises doctors of their responsibility. Sometimes fears are allayed. In the tobacco industry there are only slight degrees of nicotine poisoning in new entrants. Most nicotine poisoning arises not from the work but from the liberal supply of free cigars and cigarettes given at present to employees. Although nicotine acts on the smooth muscle of the gravid uterus, the suggestion that it causes abortion in tobacco workers is discounted. Other causes of miscarriage in the many unmarried workers should not be overlooked.

This pinpointing of the hazards forms the background to the most important parts of the book covering the preventive and protective measures. These are of three types-technical, legal, and explanatory. The technical measures are well illustrated in the section on welding. The general precautions are directed against burns and electric shock. The specific precautions are the glasses, shields, etc. fitted with appropriate type of glass to protect the eyes of the welder or those near him from radiations produced by the electrode. Provision must be made for removing poisonous fumes or dust, such as lead and cadmium, coming from the welded metal. The legal and explanatory measures include legal enactments and regulations made by trade associations in West Germany as well as many leaflets and pamphlets giving instructions, advice, and explanations to employers or workers. These are in small print and in all probably comprise about a third of the text. These are certainly of great value to the factory doctor in Germany. Dr. Koelsch thinks they may serve as models for other countries where regulations have to be made. The legal enactments cover general hygienic conditions, hours of work, provision of first aid, the employment of women and young persons, and, in many cases, the provision of medical supervision. Initial and periodical examinations including chest radiographs may be prescribed, as in the ceramic industry. In some instances the precise type of medical examination is set forth in detail as in the blood examinations in processes involving exposure to lead and in those where there is exposure to X-rays or radioactive material in non-medical work. Some of the leaflets addressed to the employees take the form of appeals to them to look after their health and use all the safety methods such as spectacles, gloves, protective clothing and so on placed at their disposal by the firm.

This outline of the book is to show the scope of its contents. No doubt it will be important to those interested in occupational medicine in Germany. Elsewhere and especially in countries where occupational medicine has advanced it will only be referred to occasionally. It is no disparagement to the immense labour of the veteran Dr. Koelsch to say one doubts the merit of this particular type of book. The works doctor must possess a good grounding in industrial medicine, such as is comprised in volume $\mathrm{I}$. He must then have an intimate knowledge of the processes and present hazards in his own works, and be a soothsayer of future ones. All these form his textbook.

Charles L. SutherLand

\section{Notice}

\section{International Conference on} The Prevention of Occupational Risks

The General Secretariat of the International Social Security Association (I.S.S.A.) announces that an International Conference on the Prevention of Occupational Risks will be held in Hamburg from September I4 to $17,1966$.

The conference will be organized by the International Committee on the Prevention of Occupational Risks in co-operation with the member institutes of the I.S.S.A. of the Federal Republic of Germany; the main items on the agenda will be ( $I$ )Prevention of commuting accidents; and (2) Prevention of accidents in the home. 